\title{
Structural optimization of conceptual aerospace vehicles
}

\author{
G. A. Hrinda \\ NASA Langley Research Center, USA
}

\begin{abstract}
Aerospace vehicle structures must be optimized for mass to maximize the mission payload. During the conceptual design phase, structures must be optimized to accurately predict the mass of the design. Analysis methods that are used in sizing members should allow for the selection of a variety of metallic and composite materials and user-defined geometry constraints. Rapid vehicle structural analysis is often necessary to improve the fidelity and the results that are obtained during the preliminary design. Recent experiences are highlighted that utilize the Collier Research Corporation's Hypersizer ${ }^{\circledR}$ toolset to optimize structural concepts.
\end{abstract}

Keywords: finite-element analysis, optimization, conceptual design, composites.

\section{Introduction}

NASA's retirement of the Space Shuttle in 2010 and the goals for advancing human space exploration have led to many opportunities for designing new spacecraft structures [1]. The ability to carry a mission forward by developing credible structural estimates in a short design cycle has become vital to mission planners. Traditional methods of analysis that use detailed finite-element models (FEM) can and have delayed concept development; thus, the search for tools that can quickly size structures has increased. Analysis methods must emphasize structural components that define major load paths and major weight contributors.

A structural tool also should easily define the best materials that lead to a lightweight design. This includes simultaneously choosing the optimizing geometry and matching it to a metallic or composite material. The ease with which a tool can perform an optimization will impact the quality of the structural design that is provided to mission planners. 
The structural optimizing tool Collier Research Corporation HyperSizer ${ }^{\circledR}$ meets the analysis requirements that are mentioned above and is used here to evaluate three spacecraft structural concepts. Structural weight reduction is performed without the use of an FEM optimization procedure. Three detailed structural concepts using bladed-stiffened, honeycomb, and laminated panels are used in conceptual designs for a lunar descent Module (DM), a composite crew module (CM) and a human Mars aerocapture vehicle.

\section{Analysis methodology}

All of the sizing for the three structures that are discussed in this paper is performed with the Hypersizer analysis software toolset. The vehicles are analyzed within a trade space with the use of metallic and composite materials with varying stiffened panel and beam cross-sectional geometry. Optimum laminate stacking and honeycomb sandwich geometries were selected by the tool to quickly identify the lightest structural component and material to satisfy the design margins.

The analysis method starts with the creation of a coarse meshed FEM NASTRAN loads model. HyperSizer uses internal panel and beam forces and moments that are computed from NASTRAN for sizing optimization and for identifying failures in the structure. The sizing tool uses equivalent panel formulations where complex three-dimensional (3-D) panel shapes are reduced to accurate two-dimensional (2-D) planar elements. Equivalent $6-\times-6$ stiffness matrices are used to represent the group of finite elements that make up the HyperSizer panel [2]. The panels are represented in NASTRAN by the cquad4 and ctria3 planar elements. The pshell card is used to define the properties for these elements, and the mat 2 card is used to define the material properties. HyperSizer automatically generates the generalized stiffness for the panels and exports the appropriate pshell and mat 2 cards into separate files for analysis in the NASTRAN loads model. The iterative process of exchanging element-force and element-stiffness data is repeated until the design converges and all margin checks are met. The checks that are performed include discrete panel buckling and crippling in addition to beam-stiffened panel checks that include facesheet wrinkling and honeycomb core dimpling.

\section{Examples of optimized conceptual vehicles}

The following three vehicles are notional examples for which Hypersizer was used to quickly analyze and optimize structures during the conceptual design phase. The vehicles represent typical designs done for trade studies that were recently conducted for future NASA missions.

\subsection{Mars human aerocapture mission}

NASA has been developing reference architecture for the first human mission to Mars; this reference architecture includes an emphasis on trade studies that may 
help the mission [3]. One of those studies investigates an aerocapture human mission at Mars. The aerocapture mission uses the Martian atmosphere to slow an entry aeroshell without any chemical propulsion. Reducing the mass of the entry vehicle by eliminating chemical propulsion for orbital capture was the goal of the study. Eliminating a major propulsion system could increase the landed mass to the Martian surface and lower mission costs.

\subsubsection{Mars human aerocapture analysis}

The Mars human aerocapture mission study uses a new Ares V launch vehicle with a 10-m (32.8-ft) shroud diameter [4]. The new heavy-lift launch vehicle is included in the NASA Constellation architecture and is currently under development. The launch shroud of the Ares $\mathrm{V}$ was designed with a dual role for the Mars mission. It is the primary structure that supports the mission payload during launch and also serves as the aeroshell for aerocapture at Mars. The payload mass is supported by a series of internal arch panels that smoothly transfer loads into the outer shroud skin/stringer design.

The arrangement of the mission payload inside the shroud was unknown during the design study, so six concentrated masses totaling 56,391 $\mathrm{kg}(124,321$ lb) were used. The masses were distributed along the centerline of the vehicle; each was placed on the apex of an arch support.

The vehicle structure was sized for an Ares V launch and for aerocapture loads. The assumed launch loads (5-g axial and 2-g lateral) were simultaneously applied as equivalent static loads. The aerocapture loads were normal aero pressures and were applied to the windward side of the aeroshell. The pressures were derived from a computational fluid dynamics analysis, based on one point along the aerocapture trajectory at Mars [5]. An estimated nonstructural mass of $0.0023 \mathrm{~kg} / \mathrm{cm}^{2}\left(4.718 \mathrm{lb} / \mathrm{ft}^{2}\right)$ was applied to the aeroshell to account for the thermal protection system that is required for the Martian aerocapture.

Two Hypersizer models were used to size the different structural configurations that are required for launch and aerocapture. The first model, shown in figure 1, was sized for an Ares V launch. The model was supported with pinned connections at the base where an Earth departure stage would be attached. The stage was not a part of the study; however, it may be included in future work.

Figure 2 shows the second Hypersizer model that was used for sizing the aerocapture structural configuration. The model was created with a portion of the launch shroud removed. The omitted structure represents the shroud structure that is jettisoned after launch. The lighter shroud reduces the mass that is necessary to reach Mars and also provides a clear path for deploying the mission payload at Mars.

\subsubsection{Mars aerocapture sizing results}

The structural sizing results for the Mars aerocapture vehicle that were obtained from the Hypersizer analysis are given in figures 1 and 2 . The final total weight result for the vehicle structure at launch is $27,152.0 \mathrm{~kg}(59,860 \mathrm{lb})$. The total launch shroud weight is $8,237.1 \mathrm{~kg}(18,159.8 \mathrm{lb})$. The optimal shroud skin recommended by Hypersizer is honeycomb with composite facesheet layup. 


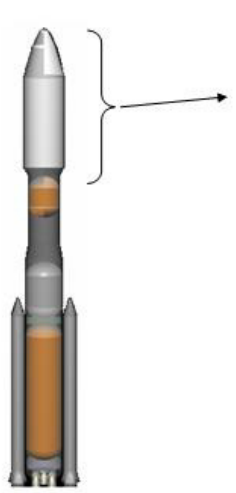

ARES V

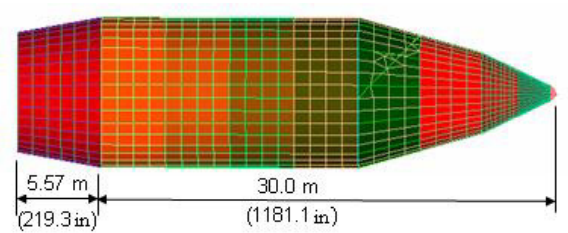

Shroud structure

$8,237.1 \mathrm{~kg}$

$(18,159.8 \mathrm{lb})$

Beam structure

$13.979 .3 \mathrm{~kg}$

$(30,819.1 \mathrm{lb})$
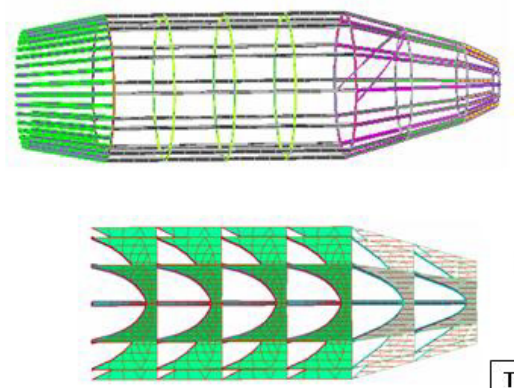

Arch structure $4,935.8 \mathrm{~kg}$ $(10,881.5 \mathrm{lb})$

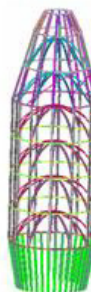
$(59,860 \mathrm{lb})$

Figure 1: A concept for Mars aerocapture structure at launch.

$4,214.4 \mathrm{~kg}$

$(9,291.2 \mathrm{lb})$

$9,417.9 \mathrm{~kg}$

$(20,762.95 \mathrm{lb})$

$5,999.1 \mathrm{~kg}$

$(13,225.8 \mathrm{lb})$

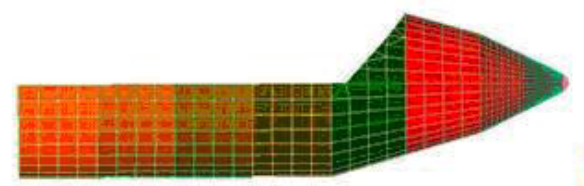

Shroud structure



Beam structure

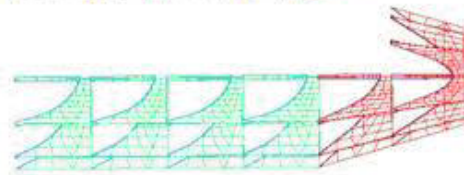

Arch structure

Figure 2: Structural configuration concept for Mars aerocapture.

The majority of the core is a honeycomb phenolic that is sandwiched between graphite epoxy facesheets. The frustum of the shroud is an exception that requires a switch to a stiffer skin that is made from a titanium core with aluminum facesheets.

The beam structure that is shown in Figure 1 accounts for $13,979.3 \mathrm{~kg}$ $(20,819.1 \mathrm{lb})$ of the total launch weight, with the internal arches adding an additional $4,935.8 \mathrm{~kg}(10,881.5 \mathrm{lb})$. The longitudinal stringers are t-shapes of various sizes and materials. The first stringer, which is set at the nose of the 
shroud, is graphite polymide. The stringer material changes to aluminum along the length of the shroud to help carry the loads from the arch supports. An additional increase in shroud loads at the frustum requires titanium stringers.

The final total aerocapture structural weight is $19,631.4 \mathrm{~kg}(43,280 \mathrm{lb})$. Figure 2 gives a breakdown of the weights for each structural component of the vehicle. The shroud weight during aerocapture is reduced to 4,214.4 $\mathrm{kg}(9,291.2$ lb). The weights of the beams and arches are also reduced to $9,417.9 \mathrm{~kg}(20,763$ lb) and 5,999.1 kg (13,225.8 lb), respectively.

The weights of the major structural members for the launch and aerocapture configurations are summarized in Table 1.

Table 1: $\quad$ Final structural masses.

\begin{tabular}{|l|l|l|l|l|}
\hline Configuration & \multicolumn{1}{|c|}{ Shroud } & \multicolumn{1}{|c|}{ Beams } & \multicolumn{1}{c|}{ Arches } & \multicolumn{1}{|c|}{ Total } \\
\hline Launch & $8,237.1 \mathrm{~kg}$ & $13,979.3 \mathrm{~kg}$ & $4,935.8 \mathrm{~kg}$ & $27,152.0 \mathrm{~kg}$ \\
& $(18,159.8 \mathrm{lb})$ & $(30,819.1 \mathrm{lb})$ & $(10,881.5 \mathrm{lb})$ & $(59,860 \mathrm{lb})$ \\
\hline Aerocapture & $4,214.4 \mathrm{~kg}$ & $9,417.9 \mathrm{~kg}$ & $5,999.1 \mathrm{~kg}$ & $19,631.4 \mathrm{~kg}$ \\
& $(9,291.2 \mathrm{lb})$ & $(20,762.95 \mathrm{lb})$ & $(13,225.8 \mathrm{lb})$ & $(43,280 \mathrm{lb})$ \\
\hline
\end{tabular}

\subsection{Lunar descent module}

NASA's goal to return humans to the moon by 2020 will require a series of unique vehicles to perform mission critical operations [6]. One vehicle, the lunar descent module (DM), lands a crew and payload to the lunar surface. A design study of this vehicle was conducted to investigate the primary structure that will be necessary to support mission requirements.

\subsubsection{DM analysis}

The DM design used various panel concepts that were optimized with HyperSizer. Figure 3 shows the major system level components of the vehicle; the weights of these major components are listed in Table 2. The components include an ascent module (AM) that is used to return astronauts from the lunar surface and a habitat module (HM) that provides an extended stay on the surface. The heaviest components are four liquid oxygen (LOX) tanks that weigh 21,395 $\mathrm{kg}(47,168 \mathrm{lb})$. Each was vertically aligned with an Earth departure stage (EDS) adapter to allow an axial load path through four hard points. All of the components were treated as lumped masses in the Hypersizer model.

An existing DM geometry is sized for launch and translunar injection (TLI) loads. The launch loads (5-g axial and 2-g lateral) were simultaneously applied. Ignition of the EDS produced the TLI forces and moments that are shown in Figure 4.

\subsubsection{DM sizing results}

The primary structural weight that is found with Hypersizer is $1034 \mathrm{~kg}(2279 \mathrm{lb})$. The analysis uses aluminum and titanium honeycomb panels of varying core 
density and facesheet thickness. The largest core thickness is $1.25 \mathrm{in}$. Over half of the structural weight comes from the panels that are sized for launch loads. A large opening in the structure that is required for the HM caused a decrease in lateral bending stiffness and drove an increase in panel size and weight.
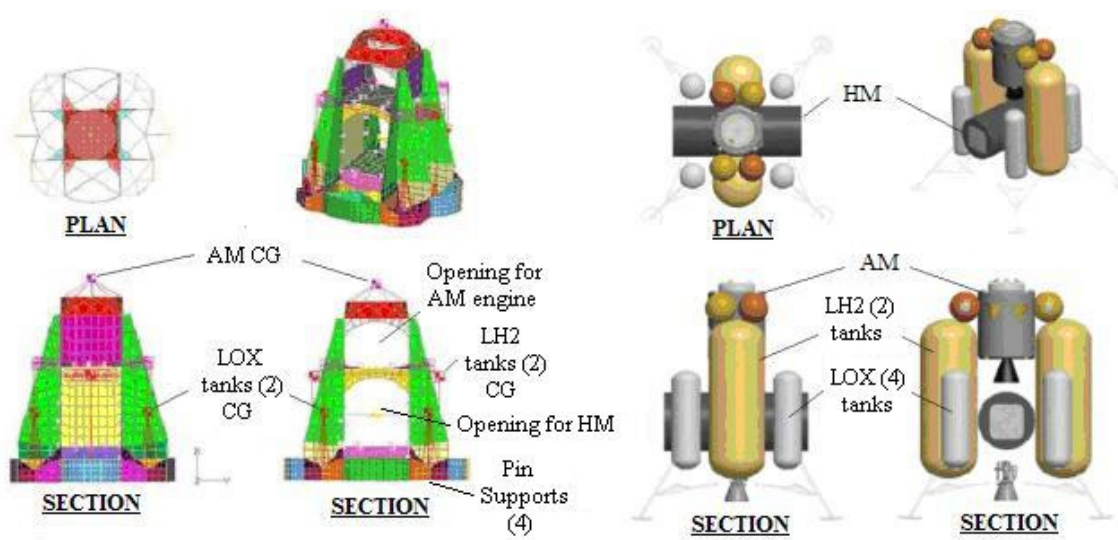

Figure 3: $\quad$ Lunar descent module Hypersizer model and geometry.

Table 2: $\quad$ Major system-level components of a Lunar lander concept.

\begin{tabular}{|l|c|}
\hline \multicolumn{1}{|c|}{ Component } & Weights kg (lb) \\
\hline Ascent module (AM) & $6441(14,200)$ \\
\hline Habitat module (HM) & $5080(11,200)$ \\
\hline DM engine & $171(376)$ \\
\hline LOX tanks (4) & $21,395(47,168)$ \\
\hline LH2 tanks (2) & $4010(8,840)$ \\
\hline Nonstructural mass (NSM) & $4316(9516)$ \\
\hline TOTAL & $41,413(91,300)$ \\
\hline
\end{tabular}

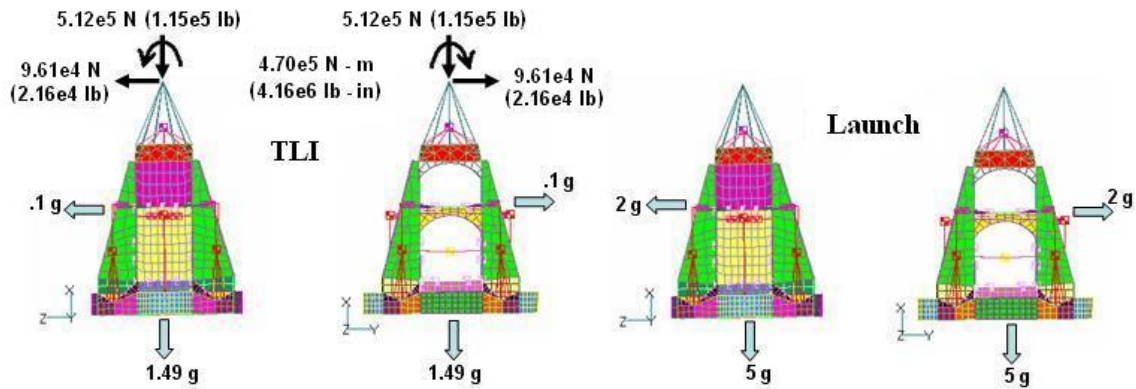

Figure 4: $\quad$ TLI and launch loads that were used to size the DM structure. 


\subsection{Composite crew module}

A NASA design study was conducted to investigate the use of composites in constructing the Orion crew module (CM) structure [7]. The objectives of the study were to develop an optimized composite CM and identify known and anticipated design and analysis issues with a composite CM. The composite design was based on a 5-m (16.4-ft) diameter requirement for the Orion structure and also on the same load cases. The CM geometry and launch abort system (LAS) were modified from the latest Orion baseline design to take advantage of composites. The Hypersizer toolset was utilized to quickly determine whether a composite design for the CM was feasible.

\subsubsection{CM analysis}

The CM Hypersizer analysis uses inertial relief with a notional 15-g LAS load and a simultaneously applied internal cabin pressure of $104.8 \mathrm{kPa}$ (15.2 psi) [8]. The LAS load is applied as an equivalent static load of 200,328 $\mathrm{kg}(441,647 \mathrm{lb})$ that is distributed into the four gussets as shown in Figure 4. The pressurized $\mathrm{CM}$ cabin geometry is derived from the Apollo pressure vessel. The CM edges are rounded, as shown in Figure 5, to better accept a composite material design. The FEM is a coarse-grid model that is constructed with separate panel groups for sizing in Hypersizer. The groups are shown in Figure 6 and are limited to panel concepts with honeycomb and composite laminates.

\subsubsection{CM results}

The Hypersizer results for the different panel groups are shown in Figure 7 . The total structural weight of all of the panels is $524 \mathrm{~kg}(1156 \mathrm{lb})$. The panels are composed of aluminum honeycomb cores of varying thicknesses with layups of graphite epoxy facesheets. Also sized are aluminum beams that weigh $42 \mathrm{~kg}$ (92 lb). The beams are included to address concerns of mounting equipment. The total CM structural weight of all panels and beams is $566 \mathrm{~kg}$ (1248 lb).

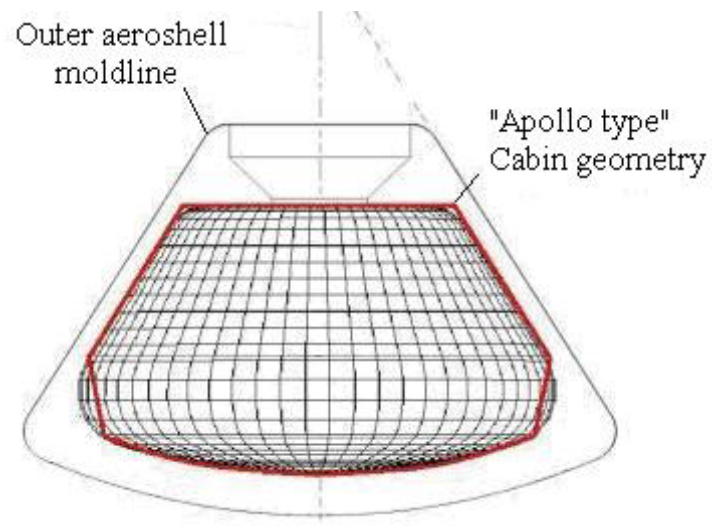

Figure 5: $\quad$ CM geometry change for composite design and LAS loads. 

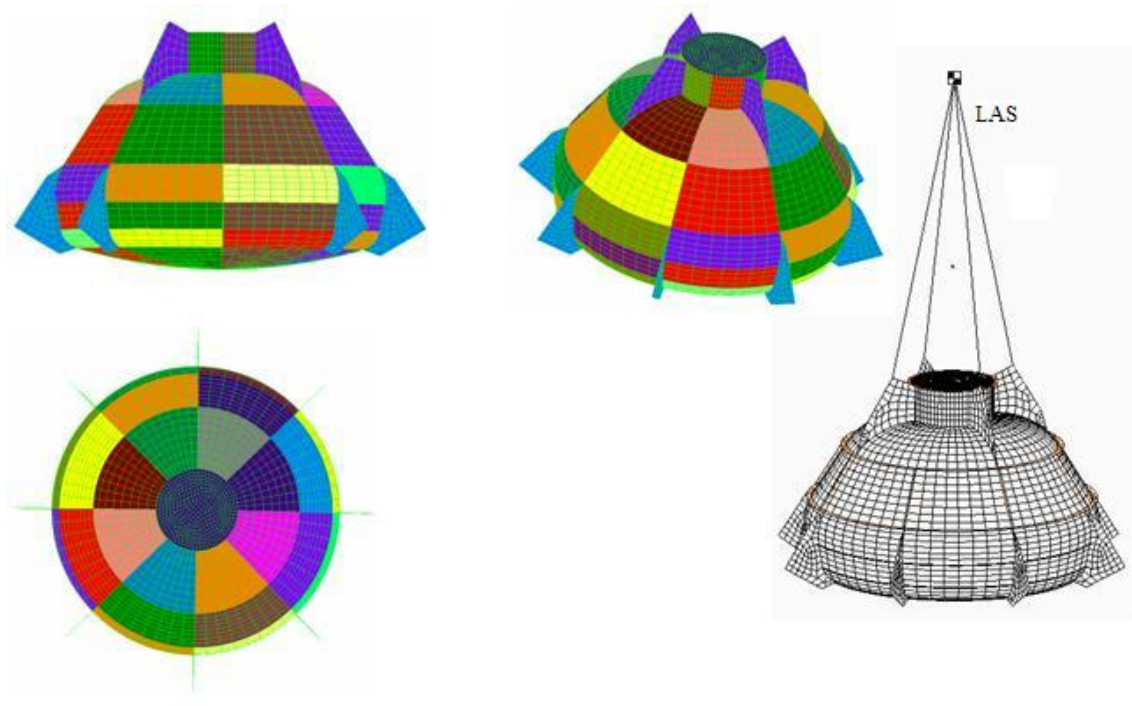

Figure 6: Hypersizer model that shows panel groups and the LAS.

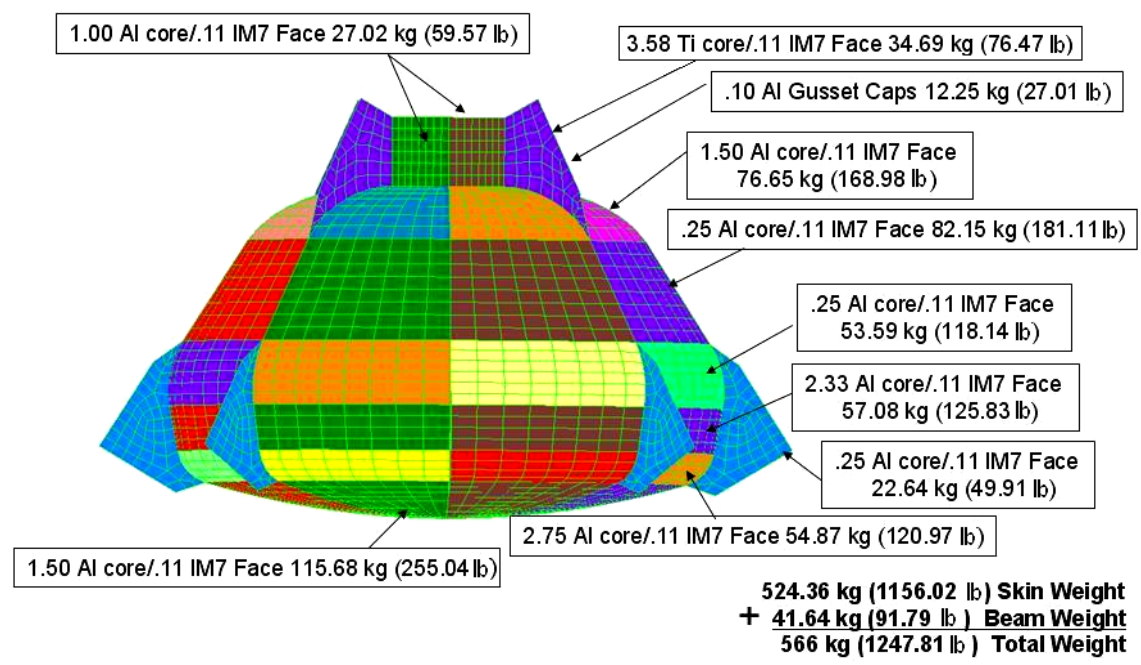

Figure 7: $\quad$ Composite CM Hypersizer results.

\section{Conclusion}

The structures of three conceptual vehicle designs were analyzed and sized with a nondeterministic sizing tool called Hypersizer. The conceptual design process was enhanced by the tool's capability to narrow the material trade space by selecting candidate composites from a large database and then recommend an 
optimal composite material and geometry. Densely meshed FEM's were not required to test complex composite panel concepts, such as blade-stiffened and laminated concepts. Various combinations of composites and panel concepts were analyzed with the same FEM. This feature greatly reduced the time necessary to create the FEM's that were used in the conceptual design of the three vehicles. HyperSizer enabled the structure of the three vehicles to be quickly investigated against many candidate structural systems and materials while providing the lightest design.

\section{References}

[1] Independent Assessment of the Capabilities and Technologies Identified by the Capability Requirements Analysis and Integration (CRAI) Team, NASA contract: L-70518D/NNL04A C00T, December 2004.

[2] Collier Research Corporation: HyperSizer ${ }^{\circledR}$ Tutorial and Applications, Second Edition, Collier Research Corporation, 1998.

[3] Exploration Blueprint Data Book, NASA JSC-63724, February 2007.

[4] Constellation Program: America's Fleet of Next-Generation Launch Vehicles, The Ares V Cargo Launch Vehicle, NASA Facts, FS-2007-11-156MSFC, 2007.

[5] Kinney, D. J.: Personal Communication, NASA Ames Research Center, Oct. 10, 2007.

[6] Stanley, D., Cook, S., and Connolly, J.: NASA Exploration Systems Architecture Study, NASA-TM-2005-214062, November 2005.

[7] Constellation Program: America's Spacecraft for a New Generation of Explorers, The Orion Crew Exploration Vehicle, NASA Facts, FS-2006-08022-JSC, 2006.

[8] CEV Reference Configuration Design Definition Document, Crew Exploration Vehicle Project Office, Document Number: CxP 72103, August 2006. 